\title{
SINTESIS DAN KARAKTERISASI H-ALUMINOSILIKAT SEBAGAI KATALIS SINTESIS BIOGASOLINE DARI ASAM OLEAT
}

\author{
Abdulloh Abdulloh*, Ahmadi Jaya Permana, Deasi Adhiani Farida \\ Departemen Kimia, Fakultas Sains dan Teknologi, Universitas Airlangga \\ Jl. Mulyorejo, Surabaya \\ *email: abdulloh@fst.unair.ac.id
}

Received 24 September 2019

Accepted 31 December 2019

\begin{abstract}
Abstrak
Aluminosilikat dapat digunakan sebagai katalis dalam reaksi prengkahan. Pada penelitian ini telah dilakukan sintesis katalis $\mathrm{H}$-aluminosilikat melalui metode hidrotermal dengan rasio Si/Al sebesar 20. Karakterisasi yang telah dilakukan meliputi uji XRD, FTIR, dan keasaman. Hasil XRD menunjukkan katalis $\mathrm{H}$-aluminosilikat berbentuk amorf, sedangkan pada FTIR menunjukkan ikatan Si-O-Al pada bilangan gelombang $457 \mathrm{~cm}^{-1}$. Uji situs asam menunjukkan katalis $\mathrm{H}$-aluminosilikat memiliki jumlah asam Brønsted sebesar 0.0272 $\mathrm{mmol} / \mathrm{g}$ dan jumlah sisi asam Lewis sebesar $0.0005 \mathrm{mmol} / \mathrm{g}$. Proses perengkahan asam oleat telah dilakukan pada suhu $340^{\circ} \mathrm{C}$ selama 3 jam dan 5 jam. Produk cracking yang diuji dengan GC-MS tidak menunjukkan pembentukan senyawa biogasoline.
\end{abstract}

Katakunci: H-aluminosilikat, biogasoline, situs asam Brönsted-Lewis dan asam oleat

\begin{abstract}
Aluminosilicate can be used for cracking reaction. In this study, catalyst of $\mathrm{H}$ aluminosilicate has been synthesized by hydrothermal method with ratio molar Si/Al is 20 . The characterizations has been performed by XRD, FTIR and acidity test. Characterization by XRD showed that catalyst of $\mathrm{H}$-aluminosilicate have structure amorphous, while FTIR showed $\mathrm{Si}$-O-Al bond at $457 \mathrm{~cm}^{-1}$. The acidity test showed that catalyst of $\mathrm{H}$-aluminosilicate have Brønsted acid site $0.0272 \mathrm{mmol} / \mathrm{g}$ and Lewis acid site $0.0005 \mathrm{mmol} / \mathrm{g}$. Oleic acid was cracking at $340{ }^{\circ} \mathrm{C}$ for 3 and 5 hours. The product has been analyzed by GC-MS not showed compound forming biogasoline.
\end{abstract}

Keywords: H-aluminosilicate, biogasoline, situs asam Brönsted-Lewis and oleic acid

\section{Pendahuluan}

Indonesia terancam mengalami krisis energi dalam beberapa tahun kedepan. Hal ini disebabkan karena jumlah konsumsi bahan bakar minyak (BBM), terutama bensin (gasoline) terus mengalami peningkatan. Komsumsi bensin untuk jenis premium (RON 88), pertalit (RON 90) dan pertamax (RON 92) di Indonesia tahun 2016 adalah 32,27 juta KL. Jumlah tersebut naik menjadi 33,17 juta KL pada tahun 2017 dan 34,10 juta KL pada tahun
2018. Untuk memenuhi kebutuhan tersebut pemerintah Indonesia melalui PT. Pertamina melakukan impor sebesar $15,70,17,66$ dan 18,52 juta KL berturutturut untuk tahun 2016, 2017 dan 2018 (Adi et al., 2019). Impor yang dilakukan tersebut berdampak pada inflasi dan neraca keuangan negara tidak berimbang akibat subsidi BBM untuk menghindari krisis ekonomi. Untuk menghindari permasalahan tersebut, pemerintah Indonesia mendorong upaya pencarian 
bahan bakar alternatif sebagai pengganti suplai energi berbasis minyak bumi. Salah satunya adalah dengan mensintesis biogasoline dari bahan baku yang bisa diperbarui, yaitu minyak nabati, hewani, minyak bekas atau asam lemak bebas (free fatty acid: FFA).

Katalis berbasis silika-alumina telah banyak disintesis dan digunakan untuk reaksi cracking. Pradinaputri, 2016 menggunakan katalis $\mathrm{Zr} /$ silika-alumina untuk sintesis biogasoline dari minyak pelumas bekas menghasilkan fraksi biogasoline $29,81 \%$. Trisunaryanti, 2010 menggunakan katalis berbasis silikaalumina alam, yaitu zeolit alam teraktivasi asam dan hidrotermal dapat menghasilkan fraksi bensin sebesar $68,10 \%$. Berdasarkan hal tersebut maka pada penelitian ini dilakukan sintesis biogasoline dari asam oleat melalui metode catalytic cracking menggunakan katalis berbasis silikaalumina, yaitu $\mathrm{H}$-aluminosilikat. Asam oleat dipilih karena hampir semua macam minyak nabati.

\section{Metode Penelitian}

Bahan utama yang digunakan dalam pembuatan katalis $\mathrm{H}$-aluminosilikat adalah natrium aluminat, tetraetil ortosilikat (TEOS, Merck, 98\%), etrapropilamonium hidroksida (TPAOH, Merck, 40\% dalam air), Cetiltrimetilamonium bromida (CTABr), dan ammonium asetat $\left(\mathrm{CH}_{3} \mathrm{COONH}_{4}\right)$ dan asam oleat.

Instrumen yang digunakan untuk karakterisasi $\mathrm{H}$-aluminosilikat terdiri dari $X$-Ray Diffraction (XRD) X'Pert 1 Philips dan spektrofotometer Fourier Transform Infrared (FTIR). Dalam pembuatan katalis H-aluminosilikat, digunakan peralatan pendukung lainnya seperti: timbangan analitik, hotplate, pipet, centrifuge, pengaduk, autoklaf, termometer, oven, dan alat gelas. Peralatan untuk cracking asam oleat terdiri dari seperangkat alat destilasi sederhana, serta beberapa peralatan gelas laboratorium pendukung lainnya. Instrumen yang akan digunakan untuk uji produk hasil cracking adalah gas chromatography mass spectroscopy (GC-MS).

\section{Sintesis H-aluminosilikat}

Katalis H-aluminosilikat disintesis melalui metode hidrotermal dengan komposisi molar: $1 \mathrm{SiO}$ : $0,05 \mathrm{Al}_{2} \mathrm{O}_{3}$ : 0,2 TPAOH: $38 \mathrm{H}_{2} \mathrm{O}: 3,85 \mathrm{CTABr}$. Sintesis dilakukan dengan melarutkan natrium aluminat $\left(\mathrm{NaAlO}_{2}\right)$ sebanyak 2,05 gram dalam $46 \mathrm{~mL}$ akuades. Campuran ditambah larutan TEOS dengan perbandingan mol Si/Al 20 lalu distirer selama 1 jam dan ditetesi dengan TPAOH sedikit demi sedikit. Campuran yang dihasilkan diautoklaf pada suhu $60^{\circ} \mathrm{C}$ selama 96 jam. Sol yang terbentuk, ditambah CTABr sebanyak 9,46 gram dan distirer selama 30 menit. Campuran diperam selama 3 jam dan dicuci hingga $\mathrm{pH}$ netral lalu dikeringkan pada suhu $60^{\circ} \mathrm{C}$ dan $110^{\circ} \mathrm{C}$. Selanjutnya padatan dikalsinasi pada suhu $550^{\circ} \mathrm{C}$ dengan dialiri gas $\mathrm{N}_{2}$ selama 1 jam dan tanpa $\mathrm{N}_{2}$ selama 6 jam untuk menghilangkan templatetemplate organic. Pertukaran kation dilakukan dengan mencampurkan aluminosilikat hasil sintesis sebanyak 1 gram dalam $40 \mathrm{~mL}$ larutan ammonium asetat $0,5 \mathrm{M}$ dan direfluks pada suhu $60^{\circ} \mathrm{C}$ selama tiga jam. Hasil campuran yang didapat disentrifus untuk dipisahkan dari filtratnya selama 5 menit dengan kecepatan $50 \mathrm{rpm}$ dan dikeringkan dengan oven pada suhu $110^{\circ} \mathrm{C}$ selama 12 jam. Padatan kering yang dihasilkan dikalsinasi pada suhu $550^{\circ} \mathrm{C}$ selama 6 jam. (Prasetyoko et al., 2010). Karakterisasi katalis $\mathrm{H}$-aluminosilikat dilakukan untuk menentukan keasaman katalis dan analisis struktur. Analisis struktur menggunakan XRD dan FTIR. Uji keasaman katalis menggunakan metode piridin-FTIR

\section{Uji aktivitas katalis H-aluminosilikat}

Reaksi cracking dengan memasukkan 5 gram asam oleat dan 0,5 gram $\mathrm{H}$ aluminosilikat kedalam labu reaksi yang telah dilengkapi dengan kondensor. Reaksi cracking dilakukan pada suhu $380^{\circ} \mathrm{C}$ 
selama 3 jam dan 5 jam. Setelah itu reaksi dihentikan dan sampel dicuci menggunakan $5 \mathrm{~mL}$ n-heksana. Katalis yang merupakan fasa padat dalam campuran dipisahkan dengan dicentrifuge dan fasa cair (produk reaksi dan reaktan) dianalisis dengan GC-MS untuk mengetahui jenis senyawa produk reaksi yang dihasilkan (Abdulloh et al., 2017).

\section{Hasil dan Pembahasan}

\section{Sintesis H-aluminosilikat}

Sintesis katalis $\mathrm{H}$-aluminosilikat dilakukan dengan metode hidrotermal pada suhu $80^{\circ} \mathrm{C}$ dengan perbandingan rasio Si/Al 20. $\mathrm{NaAlO}_{2}$ dilarutkan $\mathrm{H}_{2} \mathrm{O}$ dan ditambah larutan TEOS. Campuran distirer selama 1 jam lalu ditambah TPAOH yang berfungsi sebagai template organik I. Larutan diautoklaf pada suhu $60^{\circ} \mathrm{C}$ selama 96 jam untuk mengalami proses hidrotermal. Selanjutnya gel yang dihasilkan ditambah CTABr lalu diaduk selama 30 menit. Campuran yang dihasilkan didiamkan selama 3 jam agar terbentuk pori dengan ukuran yang besar. Kemudian dilakukan pencucian hingga $\mathrm{pH}$ netral lalu gel dikeringkan pada suhu $60^{\circ} \mathrm{C}$ dan $120^{\circ} \mathrm{C}$ dalam oven. Padatan amorf dikalsinasi dengan dialiri gas $\mathrm{N}_{2}$ selama 1 jam dan tanpa gas $\mathrm{N}_{2}$ selama 6 jam pada suhu $550^{\circ} \mathrm{C}$ untuk menghilangkan senyawa organik CTAB yang masih terdapat pada pada padatan amorf. (Campbell, 2006).

Aluminosilikat hasil sintesis dilakukan pertukaran kation untuk mengganti ion $\mathrm{Na}^{+}$agar dapat digunakan sebagai katalis asam. Pertukaran kation dilakukan dengan mereaksikan aluminosilikat dan larutan ammonium asetat $\left(\mathrm{CH}_{3} \mathrm{COONH}_{4}\right) \quad 0,5 \mathrm{M}$ dengan cara direfluk. Selanjutnya padatan aluminosilikat dipisahkan dari filtratnya dengan centrifuge. Padatan dikeringkan pada suhu $120^{\circ} \mathrm{C}$ selama 12 jam dalam oven. Selanjutnya dilakukan kalsinasi pada suhu $550^{\circ} \mathrm{C}$ selama 6 jam agar ion ammonium $\left(\mathrm{NH}_{4}{ }^{+}\right)$terurai menjadi ion $\mathrm{H}^{+}$ dan gas $\mathrm{NH}_{3}$ akan lepas, sedangkan ion $\mathrm{H}^{+}$ akan tetap berada dalam struktur aluminosilikat (Augustine, 1996).

\section{Karakteristik H-aluminosilikat} Hasil analisis XRD

Karakterisasi dengan XRD digunakan untuk menganalisis struktur dan kristalinitas material berdasarkan puncak kristalinitas dan kisi Kristal dengan sinar radiasi $\mathrm{Cu} \mathrm{K}_{\alpha}(\lambda=1,541 \AA)$ serta sudut $2 \theta$ $5^{0}-50^{0}$. Pada difraktogram menunjukkan bahwa padatan yang dihasilkan berbentuk amorf yang dapat dilihat dari puncak kecil namun lebar yang menunjukkan ciri khas

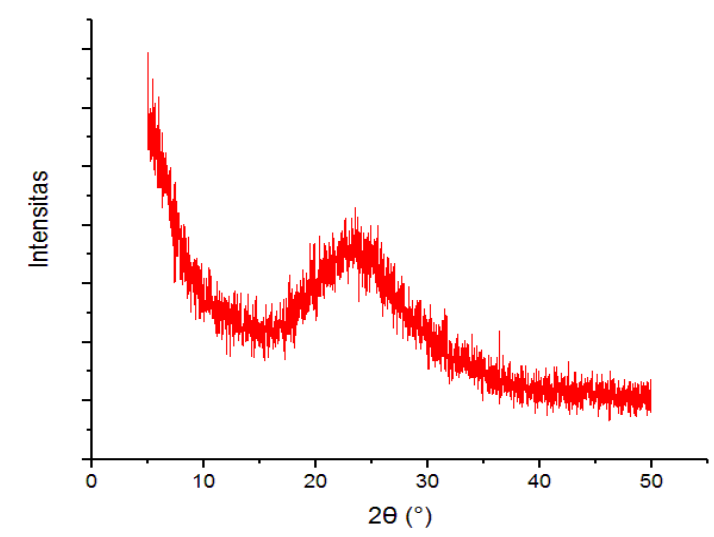

dari senyawa yang berbentuk amorf.

Gambar 1. Difraktogram XRD hasil sintesis katalis $\mathrm{H}$-aluminosilikat

\section{Hasil analisis FTIR}

Karakterisasi FTIR digunakan untuk mengamati gugus fungsi dan jenis ikatan yang dimiliki oleh sampel. Gugus fungsi katalis H-aluminosilikat pada daerah bilangan gelombang 1400-400 $\mathrm{cm}^{-1}$. Pada penelitian ini, Spektra FTIR dari sampel katalis $\mathrm{H}$-aluminosilikat menunjukkan adanya ikatan $\mathrm{T}-\mathrm{O}$ asimetrik dan simetris pada pita $1072 \mathrm{~cm}^{-1}$ dan $743 \mathrm{~cm}^{-1}$. Pada pita $457 \mathrm{~cm}^{-1}$ menunjukkan adanya vibrasi tekuk ikatan T-O. Dimana T-O adalah Si atau Al sedangakan pada bilangan gelombang $541 \mathrm{~cm}^{-1}$ menunjukkan adanya struktur MFI.

\section{Keasaman H-aluminosilikat}

Uji keasaman pada katalis dilakukan untuk mengetahui sifat asam dari katalis yang telah ditukar kation. Sampel aluminosilikat dimasukkan kedalam 
tabung gelas tahan panas yang dihubungkan pada tubular furnace dan dipanaskan pada suhu $400^{\circ} \mathrm{C}$ selama empat jam. Proses adsorpsi piridin dilakukan pada suhu kamar $\left(30^{\circ} \mathrm{C}\right)$ selama satu jam. Kemudian dilanjutkan proses desorpsi pada suhu $150^{\circ} \mathrm{C}$ selama tiga jam untuk menghilangkan piridin yang terikat secara fisis. Setelah proses ini selesai, dilanjutkan dengan analisis menggunakan instrumen IR untuk mengetahui jumlah piridin yang telah teradsopsi. Spektra IR menunjukkan puncak pada bilangan gelombang sekitar $1530-1560 \mathrm{~cm}^{-1}$ yang merupakan puncak sisi asam Brønsted. Pada bilangan gelombang sekitar 1441-1460 $\mathrm{cm}^{-1}$ menandakan adanya sisi asam Lewis pada permukaan aluminosilikat. Selain itu terdapat puncak pada bilangan gelombang sekitar $1491 \mathrm{~cm}^{-1}$ menunjukkan sisi asam Lewis dan sisi asam Brønsted. Jumlah sisi asam Brønsted dan Lewis dapat dihitung dengan menggunakan persamaan Emeis. Dari hasil perhitungan yang telah diperoleh, katalis aluminosilikat memiliki jumlah sisi asam Brønsted sebesar $0.0271 \mathrm{mmol} / \mathrm{g}$ sedangkan jumlah sisi asam Lewisnya sebesar $0.0005 \mathrm{mmol} / \mathrm{g}$.

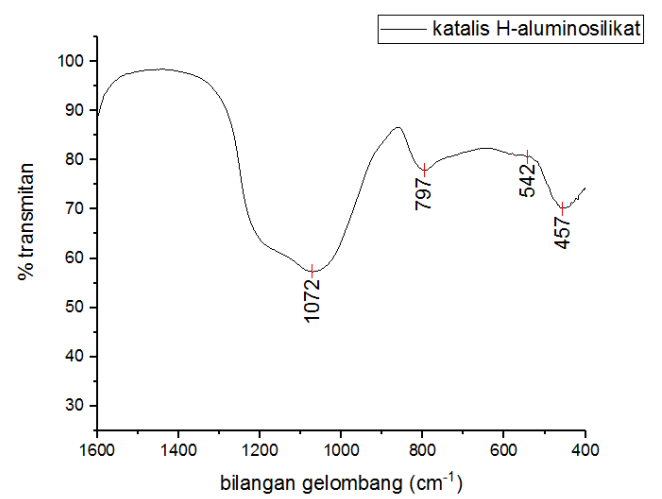

Gambar 2. Grafik spektra FTIR dari hasil sintesis katalis $\mathrm{H}$-aluminosilikat.

\section{Aktivitas katalis $H$-aluminosilikat}

Katalis H-aluminosilikat yang telah disintesis dan dikarakterisasi digunakan untuk reaksi cracking asam oleat. asam oleat sebanyak 5 gram dan katalis $\mathrm{H}$ aluminosilikat sebanyak 0,5 gram diuapkan pada suhu $380{ }^{\circ} \mathrm{C}$ menggunakan penangas pasir dengan suhu $450{ }^{\circ} \mathrm{C}$. Proses cracking dilakukan tanpa katalis dan dengan katalis dengan variasi waktu 3 jam dan 5 jam. Produk yang dihasilkan dilarutkan dengan pelarut organik nheksana, kemudian campuran larutan dan endapan katalis dipisahkan menggunakan centrifuge. Hasil cracking asam oleat menggunakan katalis $\mathrm{H}$-aluminosilikat dianalisis menggunakan instrumen GCMS.

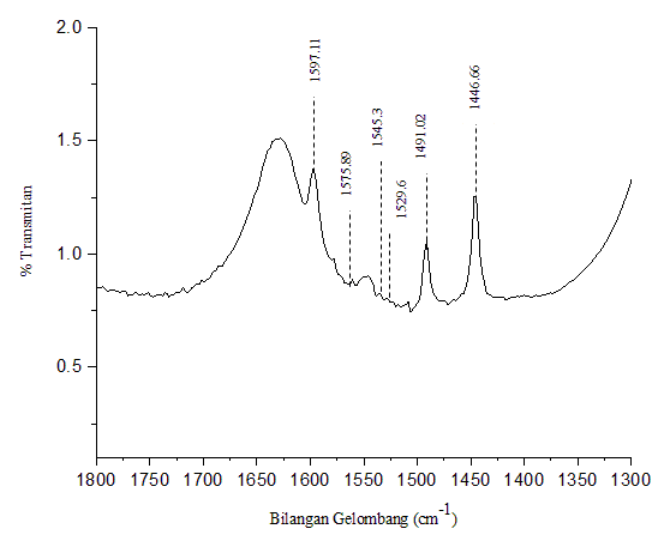

Gambar 3. Hasil uji keasaman katalis Haluminosilikat

Tabel 1. Hasil analisis reaksi cracking asam oleat tanpa katalis selama 3 jam

\begin{tabular}{rlcr}
\hline $\begin{array}{c}\text { Waktu } \\
\text { retensi }\end{array}$ & Senyawa & SI & \%Area \\
\hline 5.364 & Asam dekanoat & 98 & 7,26 \\
6.030 & tetradekana & 96 & 0,94 \\
22.871 & Asam oleat & 99 & 27,75 \\
37.764 & 1,13-tetradekadiena & 95 & 5,13 \\
\hline
\end{tabular}

Tabel 1 menunjukkan hasil cracking asam oleat tanpa menggunakan katalis. Senyawa yang dihasilakan masih berupa turunan asam karboksilat. Tabel 2 menunjukkan hasil cracking asam oleat pada variasi waktu 3 jam. Proses cracking asam oleat pada variasi waktu 3 jam menghasilkan senyawa Asam dekanoat14-metil ester dan 9-oktadekanoat metil ester. Tabel 3 menunjukkan hasil cracking asam oleat pada variasi waktu 5 jam. Pada variasi waktu 5 jam senyawa yang dihasilkan berupa 9-heksadekanoat yang memiliki rantai karbon 16, dan heptadekanolida dengan rantai karbon 17. Tabel data hasil cracking asam oleat menggunakan katalis $\mathrm{H}$-aluminosilikat memenunjukkan kesamaan dengan data hasil cracking asam oleat tanpa 
menggunakan katalis $\mathrm{H}$-aluminosilikat. Hal tersebut menunjukkan bahwa katalis $\mathrm{H}$-aluminosilikat tidak memiliki aktivitas katalitik dalam proses cracking asam oleat menjadi biogasoline.

1.

Tabel 2. Hasil analisis cracking asam oleat 2. dengan katalis $\mathrm{H}$ - aluminosilikat selama 3 jam

\begin{tabular}{|c|c|c|c|c|}
\hline $\begin{array}{l}\text { Waktu } \\
\text { retensi }\end{array}$ & Senyawa & & SI & \%Area \\
\hline 12.602 & Asam dekanoat, & & 95 & 0,16 \\
\hline 12.973 & $\begin{array}{l}\text { 9-oktadekanoat } \\
\text { ester }\end{array}$ & metil & 97 & 0,91 \\
\hline
\end{tabular}

Tabel 3. Hasil analisis cracking asam oleat dengan katalis $\mathrm{H}$ - aluminosilikat selama 5 jam

\begin{tabular}{clcc}
\hline $\begin{array}{c}\text { Waktu } \\
\text { retensi }\end{array}$ & Senyawa & SI & \%Area \\
\hline 12.970 & Asam oleat & 99 & 18.53 \\
13.136 & Heptadekanolida & 90 & 11.05 \\
13.137 & 9-heksadekenoat & 91 & 11.05 \\
\hline
\end{tabular}

Terbentuknya senyawa yang tidak sesuai dengan fraksi hidrokarbon pada biogasoline dapat disebabkan karena katalis $\mathrm{H}$-alumiosilikat memiliki sifat keasaman yang rendah serta struktur yang amorf. Rendahnya jumlah sisi asam Brønsted dan Lewis dapat disebabkan tingginya proses hidrotermal pada proses

\section{Daftar Pustaka}

Adi, A. C., Lasnawatin, F., Prananto, A. B., Suzanti, V. M., Anutomo, I. G., Anggreani, D., Yuanningrat, $\mathrm{H}$. (2019). Handbook of Energy and Economic Statistics of Indonesia 2018. Ministry of Energy and Mineral Resources Republic of Indonesia (Final Edit). Jakarta: Ministry of Energy and Mineral Resources Republic of Indonesia.

Pradinaputri, T. (2016). Sintesis katalis $\mathrm{Zr} /$ silika-alumina mesopori dari lumpur sidoarjo dan cetakan gelatin tulang sapi untuk hidrorengkah pelumas bekas. Universitas Gadjah Mada. sintesis yang menyebabkan struktur katalis menjadi tidak teratur (amorf). Katalis yang memiliki struktur amorf tidak tahan terhadap suhu tinggi sehingga sifat katalitiknya menurun (Syahrir, 2009).

\section{Kesimpulan dan Saran \\ Kesimpulan}

Katalis H-aluminosilikat hasil sintesis memiliki struktur amorf yang dibuktikan dengan puncak kecil namun lebar. Data FTIR menunjukkan adanya senyawa Si-OAl pada bilangan gelombang $457 \mathrm{~cm}^{-1}$ dan memiliki jumlah sisi asam Lewis sebesar $0.0005 \mathrm{mmol} / \mathrm{gram}$ dan jumlah sisi asam Brønsted sebesar $0.0271 \mathrm{mmol} / \mathrm{gram}$. Katalis H-aluminosilikat tidak dapat digunakan untuk cracking asam oleat dan senyawa yang dihasilkan bukan berupa biogasoline, melainkan berupa senyawa asam oleat, 9-heksadekanoat, dan heptadekenolida.

\section{Saran}

Pada penelitian selanjutnya diperlukan studi lebih lanjut mengenai metode sintesis katalis $\mathrm{H}$-aluminosilikat. Perlu dilakukan modifikasi rangkaian alat pada proses cracking sehingga dapat mengurangi penguapan senyawa-senyawa rantai pendek, dan jumlah produk yang dihasilkan dapat lebih maksimal.

Trisunaryanti, W. (2010). Selectivity of an Active Natural Zeolite in Catalytic Conversion Process of Bangkirai, Kruing and Kamper Woods Biofuel to Gasoline Fraction. Indonesian Journal of Chemistry.

Abdulloh, 2015, Preparasi dan Kajian Aktivitas $\mathrm{Al}^{3+}$ - Bentonit untuk Katalis Sintesis Biodiesel dari Asam-asam Lemak dalam Minyak Jarak Pagar, Disertasi, Universitas Gadjah Mada.

Augustine, R. L., 1996, Heterogeneous Catalysis for Chemist, Marcel Dekker Inc., New York, 23-26. 
Campbell, R., 2006, Synthesis and Characterization of ThreeDimensional Mesopori Materials, Journal of Microporous and Mesoporous Materials, 82, 145-155.

Emeis, C.A., 1993, Determination of Integrated Molar Extinction Coefficients for Infrared Bands of Pyridine Adsorbed on Solid Acid Catalysts, Journal of Catalysis, 141(2), 347-54.

Hensen, E. J. M., Poduval, D. G., Degirmenci, V., Ligthart, D. A. J. M., Chen, W., Mauge, F., Rigutto, M. S., dan Rob van Veen, J. A. 2012, Acidity Characterization of Amorphous Silica-Alumina, The Journal of Physical Chemistry, 116, 2141621429.
Prasetyoko, D., Hamid, A., Fansuri, H. dan Hartanto, J., 2010, Sintesis ZSM-5 Mesopori dengan Metode Pemeraman dan Kristalisasi: Pengaruh Waktu Kristalisasi, Seminar Rekayasa Kimia dan Proses 2010,

Wijanarko, A., Mawardi, D.A.dan Nasikin, M., 2006, Produksi Biogasoline dari Minyak Sawit melalui Reaksi Perengkahan Katalitik dengan Katalis $\gamma$-alumina, Makara Journal of Technology, 10(2), 51-60. 